\title{
Study on the Setting and Arrangement of Piano Course in Preschool Education College
}

\author{
Siwen Wang \\ Department of Humanities and International Education, Xi'an Peihua University, Xi 'an, Shaanxi \\ Province, China
}

\begin{abstract}
Piano course, as a compulsory art skill course for students majoring in preschool education, has its own particularity compared with other theoretical courses. Most of the students have no music foundation when they enter school, but after they enter the job, music activity is one of the teaching activities in kindergartens. Piano playing is an important means of music activities. Therefore, the curriculum arrangement and the setting of hours should follow the current situation step by step. Improve students' music literacy from the aspects of theory, skills, music performance and improvisation.
\end{abstract}

Keywords: curriculum orientation and function, teaching content, school hour arrangement.

\section{Course Orientation}

\subsection{Course's Position and Function in Professional Training}

Piano teaching is an important part of music education and a compulsory professional skill course for students majoring in preschool education. As a professional piano teaching in preschool education, we should carry out the principle of unity, practicability and flexibility. Starting from the characteristics of this subject, we should enable students to master the basic theoretical knowledge and basic skills of piano playing, and have better musical performance and perception ability. Modern society requires more and more educators. Kindergartens are developing towards large-scale standardization. Piano is no longer a scarce teaching equipment. Pre-school educators must have good skills to make full use of teaching equipment. Among them, improvisational accompaniment is a course that integrates music theory with keyboard skills. It requires not only the ability of playing the piano, but also the mastery of certain composing skills. It has its own unique content, rules, logic and characteristics. Through systematic teaching and training, students can master the correct methods and basic skills of piano improvisation accompaniment, improvise accompaniment for works of different genres and styles, and constantly improve their comprehensive music accomplishment.

\subsection{The Relationship between this Course and Other Courses}

This course belongs to the compulsory course of art skills. It is interdependent and mutually reinforcing with other art courses. It integrates creation and performance, and combines theory with skill. The impromptu accompaniment part must be based on solid basic music theory knowledge and skilled piano playing skills, through the transfer of tunes, musical analysis, harmony arrangement learning, so as to enhance children's ability to arrange accompaniment songs, which plays a role in promoting students'own quality training. This course undertakes the task of cultivating students'instrumental playing skills, transforming playing skills into educational skills, and cultivating students' artistic skills, artistic literacy and educational technology. Compared with other art courses, it does not have too many theoretical constraints, and pays more attention to group participation, practice and long-term practice, so as to achieve the dual goals of skills and literacy. Therefore, "Piano and Improvisational Accompaniment" course plays an important role in art courses.

\section{Teaching Objectives}

We must cultivate high-quality, applied, technical and talented teachers with high comprehensive cultural accomplishment and basic working knowledge in kindergarten, primary school and social children's art education. Integrating piano improvisation accompaniment and song playing teaching 
to improve students'practical application ability; improving teaching quality while strengthening students' piano improvisation accompaniment skills training; flexibly using diversified teaching methods to improve teaching efficiency; strengthening the integration of teaching resources and optimizing teaching evaluation system, so as to improve students'piano improvisation accompaniment ability and singing ability At the same time, students'music literacy and comprehensive ability should be improved. To cultivate students'good sense of music, self-study ability, ability to analyze and handle works. The piano lesson teaching of preschool education specialty should improve the practical application ability while grasping the basic training, so that students can truly grasp the ability to "play" and "accompany" live learning and use.

\section{Main Outline of Teaching Content}

\subsection{Learning the Basic Knowledge of Piano Playing}

First, a brief introduction to the "Piano" musical instruments; secondly, understanding the keyboard, recognizing the staff, the high and low bass clef and the stave, the name and time value of the note and rest, the types of the commonly used beat, the laws of strength and intensity, and the change of the sound mark; thirdly, to regulate the playing posture, the hand type and the fingering.

\subsection{Non-legato}

The Non-legato method refers to the method of playing with the disconnection between the sound and the sound, using the natural weight of the human body to relax the shoulder and arm, while training the support of the finger and the palm joint, which is also the basis of learning the legato method. Require you to grasp the method and key points of Non-legato playing initially, and at the same time, from one-handed playing to two-handed playing gradually.

\subsection{Legato}

Legacy refers to a method of playing without gap and coherence between sounds. The timbre is characterized by continuity and singing. Legato is the basis of expression of musical phrases. It can make the piano produce mellow, continuous and singing sound, and also develop the ability of finger skills and keys control. At the same time, we have a preliminary grasp of the playing methods and key points of the liaison.

\subsection{The Scale}

The tones in a mode, arranged in order of high and low, are called scales. In scales playing, we should solve the problem of finger-piercing and cross-finger technique, so that both hands are synchronized, the sound is bright, the timbre is uniform and smooth.

\subsection{Armature}

A string of chords is played continuously from low to high or from high to low. It can also be regarded as a kind of decomposition of chords, namely arpeggio. When playing arpeggio, we should not only solve the skills of finger piercing, finger crossing and finger enlargement, but also pay special attention to the stability of the palm to prevent twisting and rotation.

\subsection{Jumping Method}

Recognize the skipping marks and master the four methods of skipping: forearm skipping, wrist jumping, finger jumping, and rebound jumping; when playing the melody, pay attention to the coherence of the movements, so as to achieve the integrity of the sentence.

\subsection{Chromatic Scale}

A scale consisting of semitones is called a semitone. Half-tone scale divides an octave interval into twelve identical half-tone or half-tone scales, which forms the twelve-mean law. Students should 
master two octave half-scale exercises with both hands in the same direction and opposite direction, and use fingering correctly when playing.

\subsection{Ornament}

Decorative tones are generally used to enrich the tunes and add color to the music, which makes the music more distinctive. Decorative tones are divided into tremolo, relief, echo, Boeing and lower Boeing. The time value of the decorative tone is calculated within the time value of the decorative tone or the previous tone. In the learning of this knowledge point, we need to master the playing method of each decorative sound and think about how to practice it well.

\subsection{Polyphony}

There are two or more voices in the works, which are related but different at the same time. These voices are independent, but harmoniously unified as a whole. They form harmony relations with each other, and take counterpoint as the main method of creation. Such music is called polyphonic music. Polyphony music can be divided into contrastive polyphony and imitative polyphony. Through the practice of breaking up, clause and voice part, we can master this style of music.

\subsection{Palm Opening and Octave Degree}

Fifth and sixth degree exercises of both hands and then eight degree exercises, gradually adapted to the tension of hand and wrist muscles, and mastered the eight degree playing skills skillfully.

\subsection{Pedal}

The pedal is divided into the right pedal, the left pedal and the middle pedal. The right pedal is a continuation pedal, which controls the continuation of sound by opening and closing the loudspeaker; the left pedal is a weak pedal; the middle pedal is a selective continuation pedal in the triangle, which has the function of choosing resonance. When playing, the middle pedal can make the sound continue to the next key when the finger has not been raised. Continuous pronunciation produces a special resonance effect.

\subsection{Speed and Speed-up Training}

Master the skills of fast playing: reduce the height of finger lifting, do a good job of preparing for playing, penetrate all forces, find a sense of direction, adjust the breathing, improve the endurance of playing the piano and improve the playing speed at the same time. Before speed-up exercises, we must completely solve the technical problems encountered in the music, playing without any obstacles, otherwise accelerating the playing will only be counterproductive.

\subsection{Comprehensive Exercise}

Scientific and reasonable arrangement for Piano practice: careful analysis of music score before playing, practice according to correct fingering, strengthen the requirements for the effect of their own piano practice, rationally formulate the piano practice plan, attach importance to slow training, break-up exercise, part practice, phrase, segment, key and difficult practice, through listening to CD, watching video and so on, to improve the level of piano practice.

\subsection{Improvised Accompaniment}

In the teaching activities of preschool education, impromptu accompaniment is a widely used and indispensable skill. In the aspect of art, it can create images, enrich content, create atmosphere and artistic conception, highlight themes, improve students'feeling, understanding and expressive ability of songs through improvisational accompaniment, and increase students' interest in music; in the aspect of technology, it can bring into play the expressive power of piano such as harmony, sound pattern and playing method, and be more flexible and comfortable in the transfer of tunes. In the study of improvisational accompaniment, we should master the scale transposition of major and minor tones 
in the range of three litres and three falls, the chord and transposition of each scale, the function and progress of the chord, and the steps of harmonizing melody.

\section{Conclusion}

Music has a strong artistic charm. By listening to and experiencing the beauty of art, it can stimulate the emotional resonance of the public, so as to enhance people's realm, cultivate their sentiments and purify their souls. In the Outline of Guidance for Kindergarten Education (Trial Implementation), it is clearly pointed out that art is an important way to implement aesthetic education. It is necessary to give full play to the emotional education function of music and promote the formation of healthy personality of children. Therefore, the early childhood stage is the key period for music education activities, music education is an important means of human education, but also one of the most fundamental means of education. Music education can develop children's imagination, creativity, language ability and auditory ability. It is of great significance to tap children's potential, promote brain development and shape healthy and active personality.

To sum up, this requires that our students majoring in preschool education should have good musical literacy. In the process of learning piano lessons, they need to master basic piano playing, improvisational accompaniment, and singing ability. In daily teaching activities, we should integrate these teaching contents to improve students'practical application ability and teaching quality; flexibly use diversified teaching methods to improve teaching efficiency; strengthen the integration of teaching resources and optimize teaching evaluation system, so as to improve students' piano improvisation accompaniment ability and singing ability while improving students'music literacy and synthesis. Combining ability.

\section{References}

[1]. Zhang Zhonghua. Three questions about university curriculum [J]. University Education Science, 2017 (6).

[2]. Sun Yu. A comparison of chorus and conductor courses in music education between Chinese and Russian universities [J]. Huang Zhong, 2017 (3).

[3]. Dai Changliang, sun Zhao Jun. Perfect mechanism guarantee and optimize the allocation of teachers. Think about the construction of teaching staff. [J]., research on teachers in Chinese universities, 2018 (1).

[4]. Guan Yunfei. Dynamic allocation of university teachers in China based on discriminant model [J]. Systems Engineering, 2015 (6). 